\title{
Study on the mechanism and therapeutic effect of Antelope horn treatment on cerebral ischemia reperfusion injury of mouse
}

\author{
Jing WANG ${ }^{*}$, Dong JIN² (1D
}

\begin{abstract}
To the mechanism and therapeutic effect of Antelope horn treatment on cerebral ischemia reperfusion injuries under different levels of concentration. The process is as follows: (1) establish MCAO mouse model, test the modelling using traction and open field experiments, use TTC staining to detect the protective effect of Antelope horn treatment on cerebral ischemia reperfusion injury; (2) after $48 \mathrm{~h}$ of MCAO, use Nissl staining to measure the extent of hippocampal neuron damage in each group. The hippocampus corner 1 sector and dentate gyrus corner zone of hippocampal neurons of ischemia reperfusion group mouse suffered severe damages under Nissl staining detection. However, the hippocampal neurons of the medicated mouse show obvious alleviation. Western Blot results showed that, compared to the ischemic control group, the Bcl-2, Hsp 27, Hsp 27 expressions of the medicated group were significantly increased, while the Bax expression was dramatically reduced. Immunofluorescence outcome showed obvious reduction of TUNEL and FJB positive cells in the medicated group. That Antelope horn can reduce focal cerebral ischemia reperfusion injury. The reduction of degeneration and apoptosis suggests the correlation between the therapeutic effect of Antelope horn on ischemia reperfusion injury and its anti-apoptotic protective effect.
\end{abstract}

Keywords: Antelope horn; cerebral ischemia reperfusion; the protection of neurons; apoptosis; Hsp27.

Practical Application: Antelope horn can reduce focal cerebral ischemia reperfusion injury.

\section{Introduction}

Stoke, a series of diseases characterized by local neurological deficits due to brain blood circulation disorders, is one of the most serious threats to human health, ranking the no.1 disabling and no.2 killing disease (Sarkar et al., 2017; Chrzan et al., 2017). Years of medical evidence has proved that the most effective treatment is intravenous thrombolysis at 3-4.5 h after onset. Nonetheless, due to limited time window and medical conditions, few stroke patients can get such treatment. Certain modern medications are effective, but with relatively large side effects (Chen et al., 2016; Wang et al., 2016). Consequently, featuring a placid and small side effect, through regulating the body's overall situation, traditional Chinese medicine becomes an effective option and plays a significant role in improving patient's physique and delaying the progression of Parkinson's disease. Antelope horn is a traditional Chinese medicine with a good effect in removing heat and toxin, cooling blood detoxification, protecting liver, and improving eyesight. It is mainly used as an antispasmodic for detoxification swelling, heat shock epilepsy, coma spasm, eclampsia convulsions, epilepsy mad, headache, dizziness, red eyes, warm spot poison, and carbuncles sore etc.This study focuses on the application of Antelope horn in cerebral ischemia reperfusion injury model, where there may be a certain therapeutic effect.

\section{Materials and methods}

\subsection{Materials}

Cells and animals

50 C57BL/6 mice (20-15g), male, 10 weeks old, body weight $23-25 \mathrm{~g}$, purchased from the Experimental Animal Center in China.

\section{Reagents}

Antelope horn (Chinese Inspection of Biological Products and Drugs) DMEM medium (US BD Biosciences); anti-TNF- $\alpha$, IL-1 $\beta$, IFN- $\beta$ rabbit polyclonal antibodies (Cell Signaling company); rabbit polyclonal anti- $\beta$-actin antibody (Santa Cruz Biotechnology, Santa company); fetal bovine serum (US BD Biosciences); mouse anti-human Bax antibody (Abcam Inc.); mouse anti-human Bcl-2 antibody (US BD Biosciences); rabbit anti-human Hsp 27, Hsp 27 antibodies (U.S. BD Biosciences). DNA marker (Sigma, USA), DNA Loading buffer (Sigma, USA); Doppler monitor (Model PeriFlux System 5000; Perimed, Stockholm, Sweden); monofilament line 6.0 (Doccol, Redlands, CA, USA); the image analysis system (Media Cybernetics, Rockville, MD, USA), and the fluorescence microscope (Olympus, Japan). The study was approved by the Armed Police Special Medical. 


\subsection{Method}

The establishment of Middle Cerebral Artery Occlusion (MCAO) model of mice

Mice fixed on surgery board, anesthetized by $5 \%$ isoflurane; put under surgical microscope, separate subcutaneous tissue and fat layer-by-layer with ordinary forceps; carefully separate and expose the right side of the common carotid artery, the external and internal carotid arteries; detach and blow the thyroid artery branch on the external carotid artery, ligate and transect the distal end of the external carotid artery; clamp the right side of the common carotid artery and internal carotid artery with a microvascular arterial clamp, leave an indwelling suture at the near end; cut a small incision at the external carotid artery with ophthalmic scissors; insert the head-end coated monofilament line 6.0 into the internal carotid artery from the external carotid artery notches, pushed toward the upper left, at a depth of $10 \mathrm{~mm}$ from the bifurcation of the common carotid artery; as the suture tip reaches the cerebral artery, the focal cerebral ischemia begins.

At this point, the brain blood flow decreased by about $90 \%$ monitored through the Doppler detector, and the block model is successfully established, so blood flow values are recorded. After 60 minutes of ischemia, remove the suture gently, and the Doppler monitor displays cerebral blood flow returned to normal; fasten suture line of the right external carotid artery stump, stitch the skin, and then discontinue the anesthesia. Incise the skin of the sham group, expose the common carotid artery, external carotid artery and internal carotid artery; isolate and blow the thyroid branch of the external carotid artery, ligate and break off the distal end of the external carotid artery, but do not block the brain artery. C57BL/6 mice were randomly divided into five groups, with 10 in each group; A: the sham group; B: the model group (normal saline after $1 \mathrm{~h}$ ischemia); C: Antelope horn low dose group (10 mg/kg after $1 \mathrm{~h}$ ischemia); D: Antelope horn low dose group (20 mg/kg after $1 \mathrm{~h}$ ischemia); E: Antelope horn high dose group (30 mg/kg after $1 \mathrm{~h}$ ischemia). All experiments are approved by the Animal Management Committee.

\section{Traction experiment}

Hang the front paws of mice on a horizontal wire, score them by the number of hind limb grips on the wire. Mark 3 points with two hind leg gripping, 2 points for a single leg grab, 1 point for none; then rank them by total scores.

\section{Open field experiment}

Take a wooden box of $100 \mathrm{~cm} \times 100 \mathrm{~cm} \times 50 \mathrm{~cm}$, divide the bottom evenly into 16 square grids $(25 \mathrm{~cm} \times 25 \mathrm{~cm})$, and leave the top open. Conduct behavioral observation in a dark and quiet room, hang a 60 -watt bulb lighting at the height of $60 \mathrm{~cm}$ above the box. Record the number of lattices the mouse had climbed as the horizontal movement frequency; note down their standing times with hind legs, demanding forelimb $1 \mathrm{~cm}$ off the ground, while excluding the standing-and-grooming phenomena. Observation time is $5 \mathrm{~min}$ for each mouse.

\section{The measurement of infarct volume}

After 48 hours of cerebral ischemia reperfusion, conduct intraperitoneal injection with 3\% Pentobarbital sodium, expose the heart, cut a small hole in the left ventricle and put in a needle; smoothly infuse $0.01 \mathrm{M}$ PBS visibly, immediately cut the right atrium appendage; after $10 \mathrm{~min}$, carefully remove the whole brain, put into $-20{ }^{\circ} \mathrm{C}$ refrigerator for $20 \mathrm{~min}$; cut the whole frozen coronal brain into slices of $2 \mathrm{~mm}$, soak in $37^{\circ} \mathrm{C} 2 \%$ TTC $(0.2$ gTTC $+10 \mathrm{~mL}$ distilled water) solution for $15 \mathrm{~min}$, under darkness, then fix it with $4 \%$ Paraformaldehyde; measure the entire forebrain and infarct area using the image analysis system, calculate the volume using the formula: infarction rate= infarct volume/forebrain volume.

\section{Nissl staining}

Assess the extent of neuron damage after ischemia using Nissl staining. The brain removing methods are as before, replace the solution with $100 \mathrm{~mL}$ 4\% Paraformaldehyde, continue the perfusion, and fix the whole brain; gently remove the brain and embed it in paraffin, slice the paraffin coronary level skull $1.5 \mathrm{~mm}$ into $5 \mu \mathrm{m}$ thickness, then dewax and put it into $0.1 \%$ cresol violet solution for 2 min staining; Assess the damage of cell morphology and nuclei of hippocampus neurons with an optical microscope.

\subsection{Immunofluorescence detection of apoptosis (TUNEL) and neuronal degeneration (FJB)}

\section{Materials preparation}

The brain removing methods are as previously stated. Fix it in $4 \%$ Paraformaldehyde for $24 \mathrm{~h}$; transfer the whole brain tissue into $30 \%$ sucrose solution for further dehydration, and the block sinking to bottom shows the completion of dewatering. Embed the brain in OCT, make frozen slices, and preserve all the ischemic brain tissue slices in 4\% Paraformaldehyde solution.

\section{TUNEL staining}

Put the brain tissue slices on the incubation plate, PBS soaked and rinsed for $5 \mathrm{~min}$ each time, 3 times in total; incubate the slices in 3\% hydrogen peroxide/methanol solution for $10 \mathrm{~min}$; PBS soaked and rinsed for $5 \mathrm{~min}, 3$ times; place the plate on ice, add breaking agent for $2 \mathrm{~min}$ further incubation; PBS rinsed again, for $5 \mathrm{~min}$ and 3 times; add $50 \mu \mathrm{L}$ TUNEL reaction solution in the brain sheets, incubate for $1 \mathrm{~h}$ under $37^{\circ} \mathrm{C}$ darkness; discard the solution, PBS washed 5 min, 3 times; Add Hoechst solution to the plate, incubate for $5 \mathrm{~min}$ under darkness; decant the Hoechst, PBS rinsed for 5 min, 3 times; Finally, put in xylene for transparency and mount with neutral gum, take photos using confocal camera; stain the nuclei with DAPI (blue), and the TUNEL positive (green) cells are apoptotic; count the blue and green cells, using the formula blue/green $\times 100 \%$ to calculate the ratio of TUNEL positive cells. Select four quadrants of each tissue slide with highlighted background, count the number of positive cells and calculate the average of each quadrant.

\section{FJB staining}

Put the brain slices on coated slides, bake for $30 \mathrm{~min}$ in a $50{ }^{\circ} \mathrm{C}$ oven to fix them; Gently drop the $1 \% \mathrm{NaOH}$ and $80 \%$ ethanol solutions on the slices, make sure covering the whole slices, and incubate for $5 \mathrm{~min}$; wash the slices with double-distilled water, cover with $70 \%$ ethanol, and incubate for $5 \mathrm{~min}$; slightly decant the ethanol, rinse with double-distilled water for $2 \mathrm{~min}$; add $0.06 \%$ potassium permanganate into the slices, and incubate for $10 \mathrm{~min}$ 
at room temperature; discard the potassium permanganate and rinse with double-distilled water for $2 \mathrm{~min}$; soak the slices in $0.004 \%$ FJB staining solution for 20 min under darkness; discard the FJB solution, wash with double-distilled water for $1 \mathrm{~min}$, 3 times in total; put the slides in a $50^{\circ} \mathrm{C}$ oven to dry for 5-10 min; Put the slides in xylene for $1 \mathrm{~min}$ transparency; finally, mount with neutral gum, and take a confocal photography. Select four quadrants of each tissue slide with highlighted background, count the number of positive cells and calculate the average of each quadrant.

\subsection{Detect the contents of TNF- $\alpha, I L-1 \beta$, and IFN- $\beta$ in mouse serum using ELISA method}

Operate according the Boster sandwich ELISA kit manual, as following: draw in $0.1 \mathrm{~mL}$ blood and add into the 96-hole paddle precoated with rat corresponding antibody (TNF- $\alpha, \mathrm{IL}-1 \beta$, and IFN- $\beta$ ), while add only sample dilution to the zero hole; cover the microtiter plate, and incubate for $1.5 \mathrm{~h}$ under $37^{\circ} \mathrm{C}$. After that, remove the internal plate liquid, add $0.1 \mathrm{~mL}$ biotinylated anti-rat antibody solution in each hole, and incubate for $1 \mathrm{~h}$ under $37^{\circ} \mathrm{C}$; Discard the internal plate liquid, PBS washed for 3 times; Add $0.1 \mathrm{~mL}$ $\mathrm{ABC}$ working solution into each hole, and incubated for $30 \mathrm{~min}$ under $37^{\circ} \mathrm{C}$. Again, decant the liquid, PBS washed for 3 times; add $90 \mu \mathrm{L} \mathrm{TMB}\left(37^{\circ} \mathrm{C}\right.$ balanced for $\left.30 \mathrm{~min}\right)$ color liquid into each hole sequentially, and incubate for 30 min under $37^{\circ} \mathrm{C}$ darkness. The best coloration time is when 3-4 holes are gradient blue before the standard hole, while 3-4 holes are insignificantly different after the standard hole. Add $0.1 \mathrm{~mL}$ TMB stop solution into each hole, and the liquid in the microplate will turn from blue to yellow. $O D$ values were measured with a microplate reader at $450 \mathrm{~nm}$.

\subsection{Measure the BAX, Bcl-2, Hsp 27, and Hsp 27 protein expressions of different mouse groups using Western Blot method}

Decapitate the mice ( 5 in each group) and take out the ischemic brain tissues, stored under $-80^{\circ} \mathrm{C}$. Cut the samples into pieces with ophthalmic scissors, add protein lysates at the ratio of 1:5, sonicated, centrifuged for $10 \mathrm{~min}$ at $4{ }^{\circ} \mathrm{C} 12000 \mathrm{rpm}$. Decant the supernatant, after BCA protein quantitation, add $5 \times$ Loading buffer, cooked for $5-10 \mathrm{~min}$ in $100^{\circ} \mathrm{C}$ boiling water, then cool down and store under $-20^{\circ} \mathrm{C}$. Take $\beta$-actin as an internal reference. Take out $20 \mu \mathrm{g}$ sample protein and conduct $12 \%$ SDS-PAGE electrophoresis, put under a constant voltage of $100 \mathrm{~V}$ for $2 \mathrm{~h}$ and transfer to a nitrocellulose membrane, close under room temperature with 5\% skim milk. Then add rabbit anti-TH polyclonal antibody (1:1000), Bax antibody (1:500), Bcl-2 antibody (1:500), Caspase- 3 antibody (1:500) and rabbit polyclonal anti $\beta$-actin (1:1000) for $4{ }^{\circ} \mathrm{C}$ overnight incubation. On the next day, after room temperature restored for $1 \mathrm{~h}$, wash with TBST containing 1\% Tween-20 for 3 times, 10 min each time; add 1: 5000 HRP-conjugated secondary goat anti-rabbit antibody, incubated for $1 \mathrm{~h}$ under room temperature. Then wash with TBST for 3 times, 10 min each, and conduct ECL luminescence detection.

\subsection{Statistical analysis}

The results were analyzed using unpaired student's t test in the SPSS19.0 software(SPSS Inc, Chicago, IL, USA). Data were shown as mean \pm standard deviation. $\mathrm{P}<0.05$ was considered as significant difference.

\section{Results}

\subsection{Open-field and traction experiments}

The experiment results showed that, mice of the normal comparison group can seize the wire with four limbs; while the model group mice can grasp the wire with only front paws; and the Antelope horn medicated mice can hold the wire with one or two rear claws. Contrast to the model group, the Antelope horn medicated mice scored significantly higher in the traction experiments, and the higher dose, the higher score. Both the horizontal and vertical movement frequencies were dramatically lower than that of the normal comparison group. After continuous medication, both the horizontal and vertical frequencies were drastically increased, and the higher dose, the higher effects of improvement. See Figure 1.

\subsection{Infarct volume measurement results}

As the TTC staining results showed, compared with the ischemia controlled group, the Antelope horn medicated group expressed clear decline of infarct volume, and the higher density of dose, the smaller volume of infarct. See Figure 2.

\subsection{Nissl staining detection}

The hippocampal angle zone 1 neurons of the ischemia reperfusion group were greatly damaged, and the condensation of nuclei was accompanied by the process of concentrating cell body, which also happened in the dentate gyrus neurons. After different dose of Antelope horn medication, the aforementioned damages were drastically mitigated, and the higher dose, the more effective mitigation. See Figure 3.
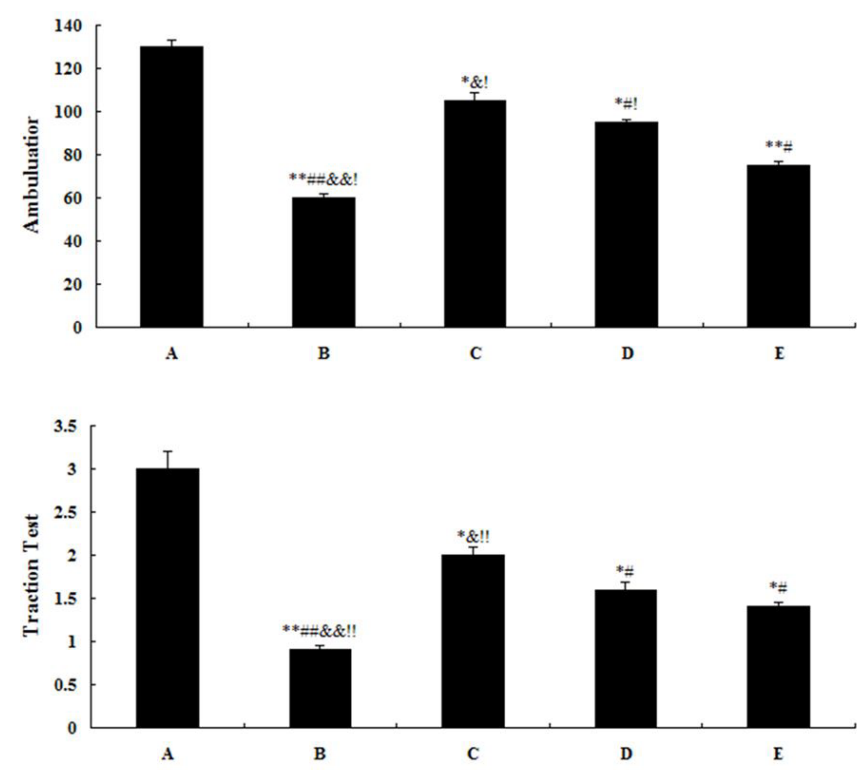

Figure 1. the open field and traction experiment results. ${ }^{*} \mathrm{P}<0.01$ vs A group; ${ }^{\star} \mathrm{P}<0.05$ vs $\mathrm{A}$ group; \#\# $\mathrm{P}<0.01$ vs $\mathrm{C}$ group; $\# \mathrm{P}<0.05$ vs $\mathrm{C}$ group; $\& \& \mathrm{P}<0.01$ vs $\mathrm{D}$ group; $\& \mathrm{P}<0.05$ vs $\mathrm{D}$ group; $! \mathrm{P}<0.05$ vs $\mathrm{E}$ group; !!P $<0.01$ vs E group. A: Sham group; B: Model group; C: Antelope horn high dose group; D: Antelope horn middle dose group; E: Antelope horn low dose group. 


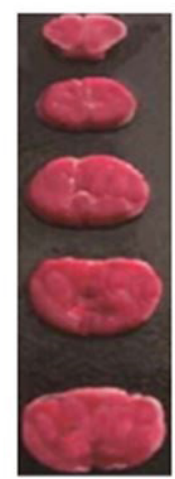

A

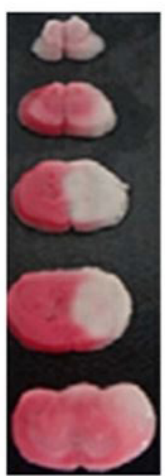

B

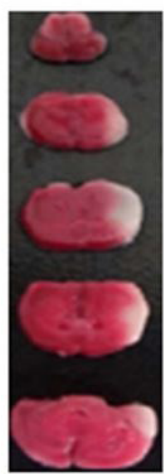

$\mathrm{C}$

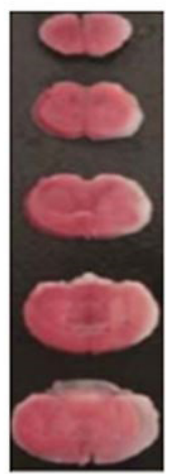

D

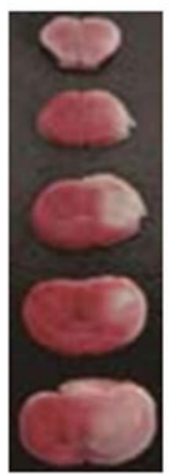

E

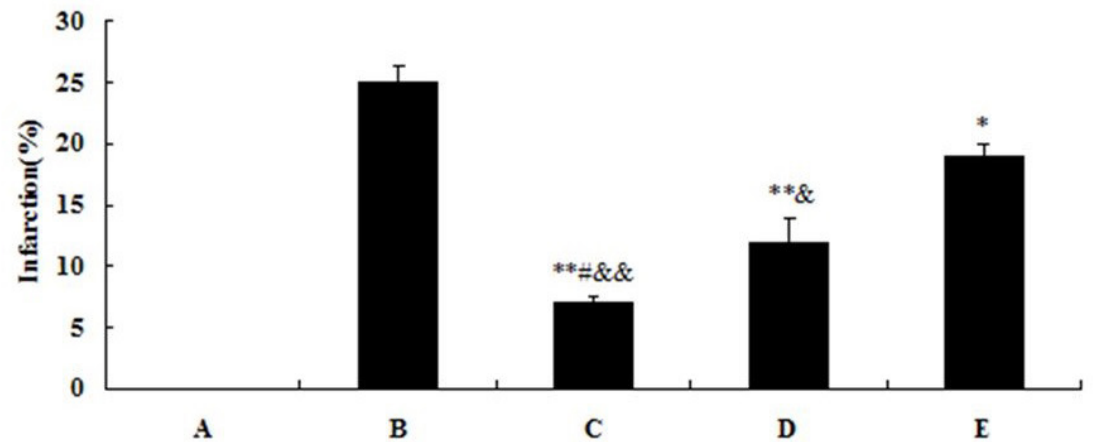

Figure 2. TTC staining results analysis. ${ }^{*} \mathrm{P}<0.01$ vs $\mathrm{B}$ group; ${ }^{\star} \mathrm{P}<0.05$ vs $\mathrm{B}$ group; $\# \mathrm{P}<0.05$ vs $\mathrm{D}$ group; $\& \& \mathrm{P}<0.01$ vs $\mathrm{E}$ group; $\& \mathrm{P}<0.05$ vs $\mathrm{E}$ group. A: Sham group; B: Model group; C: Antelope horn high dose group; D: Antelope horn middle dose group; E: Antelope horn low dose group.

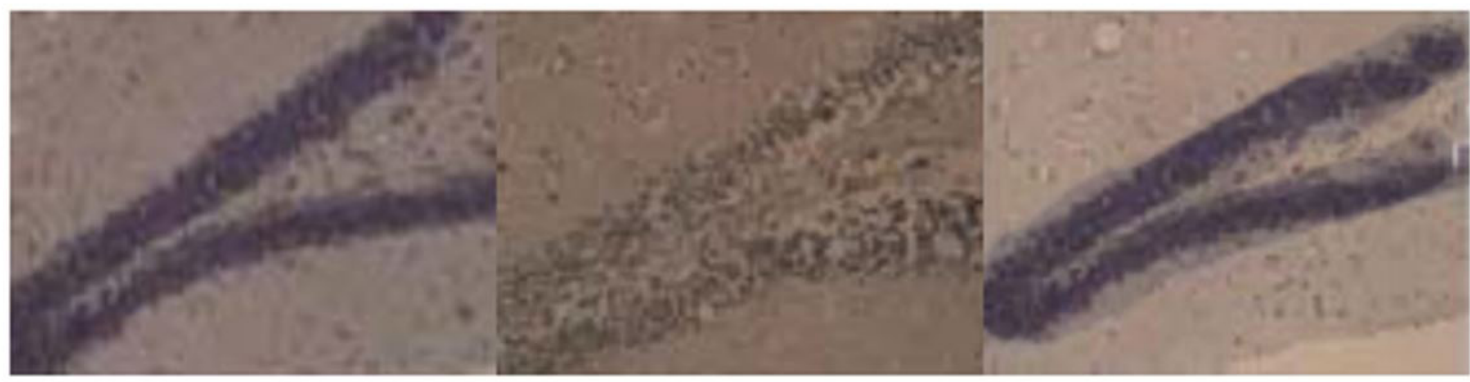
A
B
$\mathrm{C}$

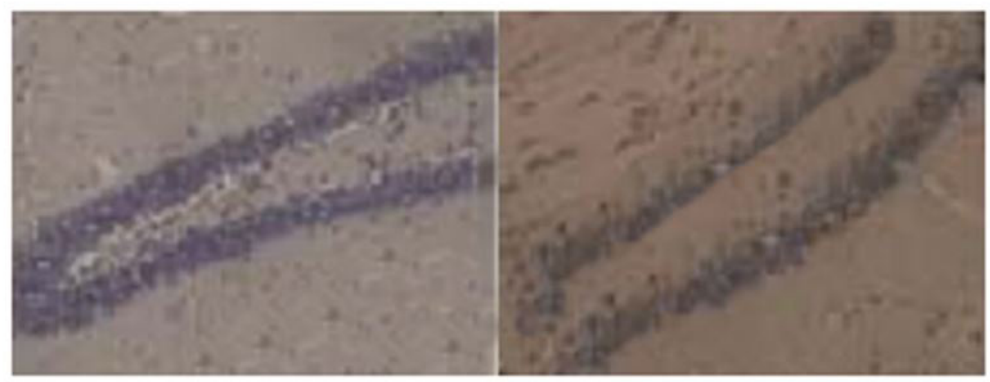

D

$\mathrm{E}$

Figure 3. Nissl staining results. A: Sham group; B: Model group; C: Antelope horn high dose group; D: Antelope horn middle dose group; E: Antelope horn low dose group. 


\subsection{Hoechst 33258 staining results}

The Hoechst 33258 staining results showed that, compared with the ischemic control group, the medicated group with different dose of Antelope horn expressed significant reduction of TUNEL-positive cells in ischemic brain tissue. See Figure 4.

\subsection{FJB staining results}

Compared with the ischemia control group, the Antelope horn medicated group presented significant reduction of FJB positive cells in the ischemic brain tissue, but more than that of the sham group. In addition, the higher dose density, the lesser FJB positive cells. See Figure 5.

\subsection{Detect the contents of TNF- $\alpha, I L-1 \beta$, and IFN- $\beta$ in mouse serum using ELISA method}

After cerebral ischemia reperfusion, cytokines like TNF- $\alpha$ in serum were largely reduced. Consequently, we detected the expressions of pro-inflammatory and anti-inflammatory cytokines. The measurement results showed that the TNF- $\alpha$ and IL- $1 \beta$ levels of the medicated group were dramatically decreased, compared with the ischemia reperfusion group, but the expression of IFN- $\beta$ was significantly increased. See Table 1.

\subsection{Western blot test results}

Apoptotic death pathway plays an important role in the cerebral ischemic injury. Bcl-2 is anti-apoptotic, while Bax accelerated apoptosis. We detected the expressions of $\mathrm{Bcl}-2$ and Bax in ischemic brain tissue using Western blot method. The results suggested that, compared with the ischemia group, after $48 \mathrm{~h}$ of ischemia reperfusion, Bcl-2 in brain tissue of the Antelope horn medicated group was significantly increased; while the level of Bax was dramatically reduced. Recent evidence indicates that Hsp 27 and Hsp 27 are protective for cerebral ischemia reperfusion injury, while our tests showed the great increase of Hsp 27 and Hsp 27 levels of the medicated group, and the higher density of Antelope horn, the more effective of protection. See Figure 6.
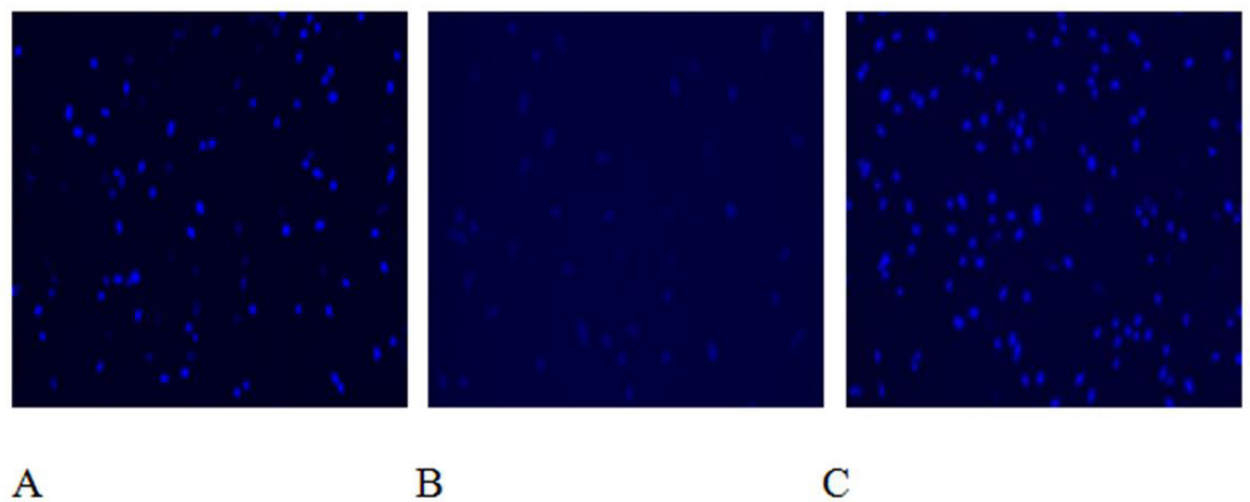

B

$\mathrm{C}$

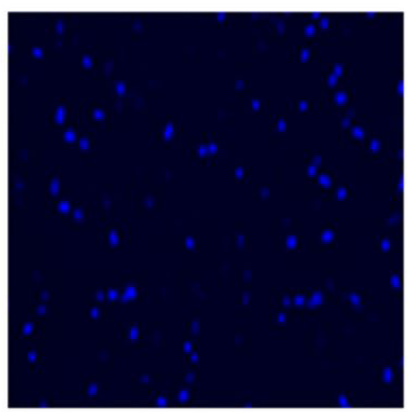

D

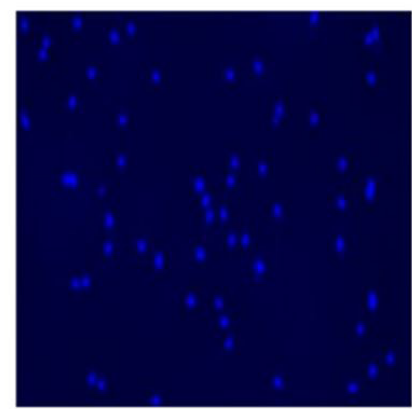

E

Figure 4. Hoechst 33258 staining results. A: Sham group; B: Model group; C: Antelope horn high dose group; D: Antelope horn middle dose group; E: Antelope horn low dose group.

Table 1. ELISA detected contents of TNF- $\alpha$, IL-1 $\beta$, and IFN- $\beta$ in mouse serums.

\begin{tabular}{|c|c|c|c|c|c|}
\hline & $\mathrm{A}$ & $\mathrm{B}$ & $\mathrm{C}$ & $\mathrm{D}$ & $\mathrm{E}$ \\
\hline $\mathrm{TNF}-\alpha(\mathrm{pg} / \mathrm{mL})$ & $11.23 \pm 0.53$ & $102.21 \pm 11.34^{! ! * * \# \# \& \&}$ & $52.98 \pm 6.99 ! ! \# \&$ & $70.92 \pm 3.22$ & $79.11 \pm 4.88$ \\
\hline $\mathrm{IL}-1 \beta(\mathrm{pg} / \mathrm{mL})$ & $9.95 \pm 1.02$ & $35.01 \pm 7.71^{! ! * * \# \&}$ & $18.33 \pm 2.07^{! \# \&}$ & $26.06 \pm 3.08$ & $29.93 \pm 5.55$ \\
\hline IFN- $\beta(\mathrm{pg} / \mathrm{mL})$ & $80.92 \pm 7.23$ & $19.83 \pm 2.03 ! ! * * \# \& \&$ & $88.34 \pm 10.93^{\# \& \&}$ & $71.10 \pm 8.29 \&$ & $53.07 \pm 6.82$ \\
\hline
\end{tabular}

!! $\mathrm{P}<0.01$ vs A group; ! $\mathrm{P}<0.05$ vs A group; ${ }^{* *} \mathrm{P}<0.01$ vs $\mathrm{C}$ group; \#\# $<<0.01$ vs $\mathrm{D}$ group; $\# \mathrm{P}<0.05$ vs $\mathrm{D}$ group; \&\&P<0.01 vs $\mathrm{E}$ group; \&P<0.05 vs $\mathrm{E}$ group. A: Sham group; $\mathrm{B}$ : Model group;

C: Antelope horn high dose group; D: Antelope horn middle dose group; E: Antelope horn low dose group. 


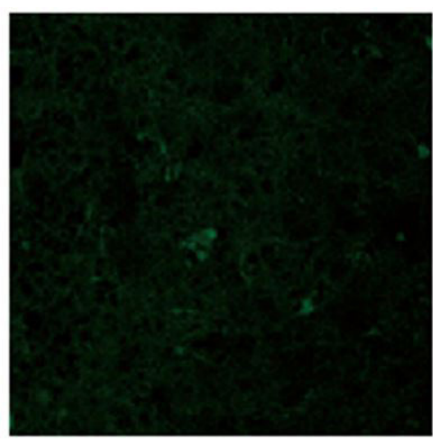

A

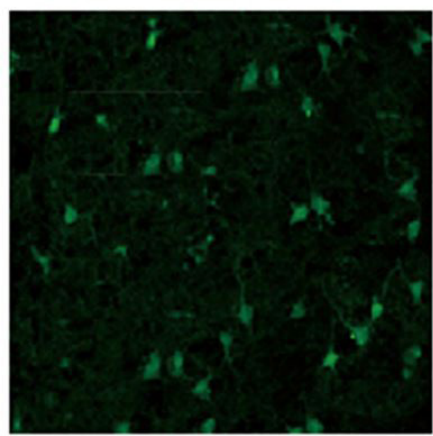

D

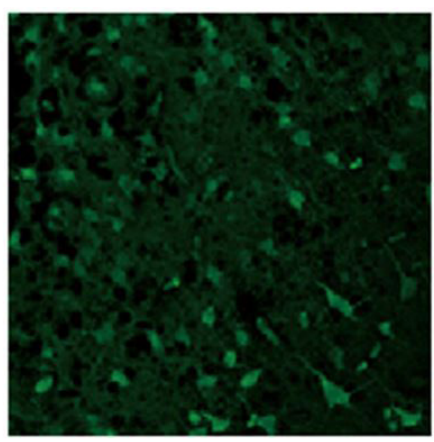

B

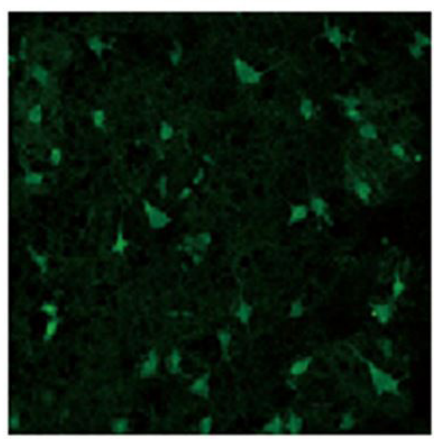

E

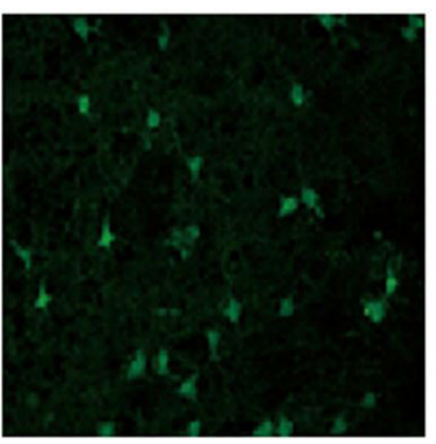

C

Figure 5. FJB staining results. A: Sham group; B: Model group; C: Antelope horn high dose group; D: Antelope horn middle dose group; E: Antelope horn low dose group.
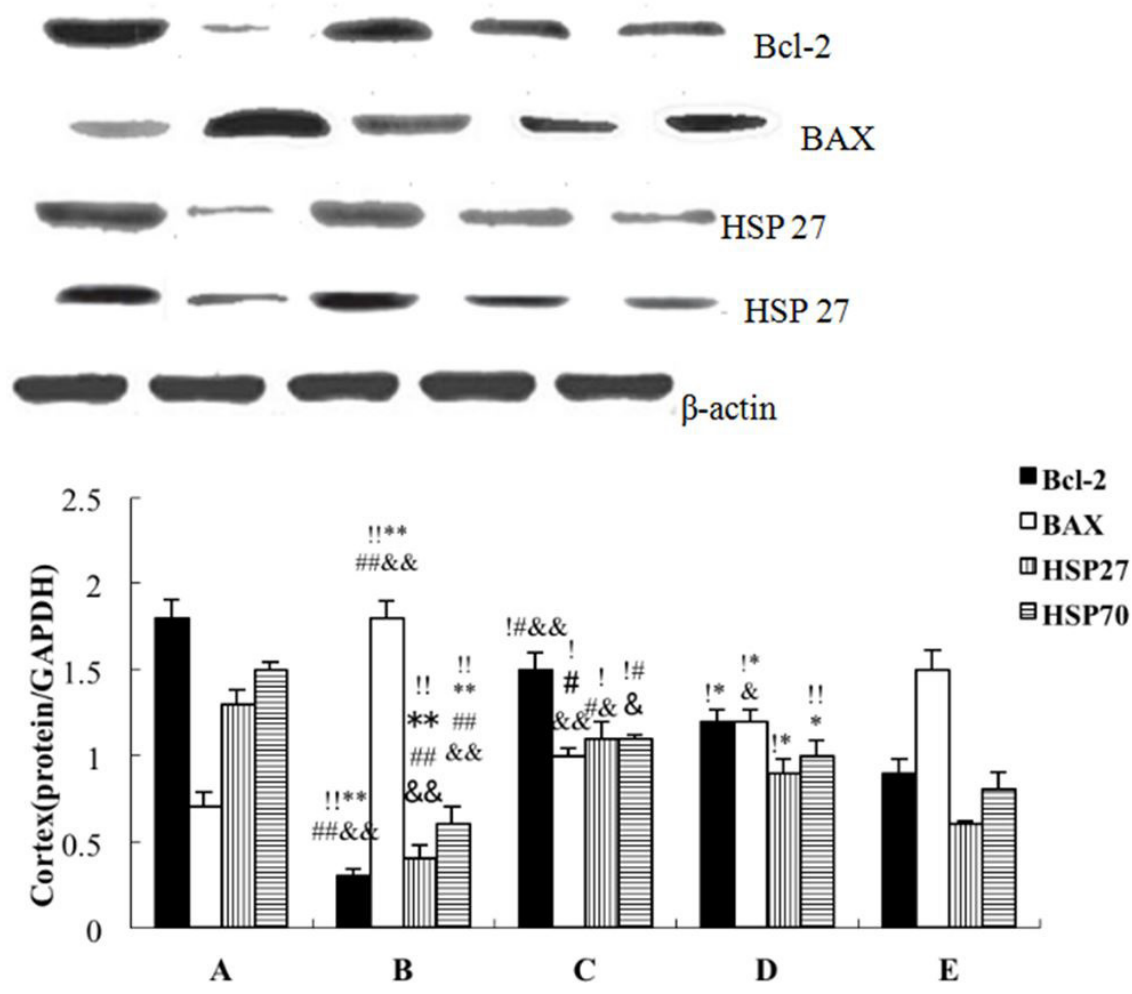

Figure 6. Proteins detection using Western blot. !! $<<0.01$ vs A group; ! $<<0.05$ vs A group; ${ }^{\star *} \mathrm{P}<0.01$ vs $\mathrm{C}$ group; ${ }^{\star} \mathrm{P}<0.05$ vs $\mathrm{C}$ group; $\# \#$ P $<0.01$ vs D group; \#P < 0.05 vs D group; \&\&P < 0.01 vs E group; $\& \mathrm{P}<0.05$ vs E group. A: Sham group; B: Model group; C: Antelope horn high dose group; D: Antelope horn middle dose group; E: Antelope horn low dose group. 


\section{Discussion}

Stroke has now become one of the major disabling and killing diseases. In the past decades, we had made great progress in the pathophysiology of stroke research. However, intravenous thrombolysis is still the only method approved by the FDA, which limited its clinical application due to the narrow time window. Moreover, recanalization can cause ischemia reperfusion injury, thus exacerbated the clinical symptoms of patients (Zhang et al., 2016). Therefore, it is urgent to find new and effective treatment. Antelope horn is a kind of traditional Chinese medicine of low toxin and high effectiveness, and our research had found its protective effect of cerebral ischemia reperfusion injury.

There has been a consensus on the involvement of neuron apoptosis in cerebral ischemia reperfusion (Gumbinger et al., 2014), and reducing apoptosis penumbra neurons can effectively mitigate neurological deficits and prevent stroke. Among these, $\mathrm{Bcl}-2$ is an important anti-apoptotic and anti-necrotic molecule, while Bax is pro-apoptotic (Fan et al., 2017a, b). It is reported that LPS can induce the apoptosis of dental pulp cells and the expression of Bax. Medication can reduce the apoptosis in doxorubicin-induced cardiomyopathy, thus increase the Bcl-2 level and decrease the Bax level. Our study is consistent with the aforementioned conclusions. In the MCAO model, the Antelope horn medicated group showed significant increase of Bcl-2 and decrease of Bax. Therefore, the protective effect of Antelope horn in cerebral ischemia reperfusion injury is correlated with the increase of Bcl-2 and decrease of Bax, as well as the reduction of neuronal apoptosis.

Current research suggests that inflammation is an influential participant factor in the pathophysiology of cerebral ischemia reperfusion injury. On one hand, inflammatory factors such as TNF- $\alpha$ and IL- $1 \beta$ activated by the microglia in the ischemic zone pose a toxic effect on ischemia brain neurons, thus exacerbate the damage of neurons (Lis et al., 2017). On the other hand, I/R can lead to the disrupt open of blood brain barrier (BBB), and peripheral infiltration of inflammatory cells into ischemic brain tissue, thus aggravate inflammatory lesions (Shichita et al., 2012). Our research showed that Antelope horn could inhibit inflammation after cerebral ischemia and mitigate ischemia reperfusion injury, suggesting that medication can relieve inflammatory cerebral ischemia reperfusion injury and improve clinical symptoms.

Heat shock protein 70 (Hsp 27) family is by far evolutionarily the most conservative protein, highly homologous from bacteria to mammals (Chen et al., 2017), thus suggests its importance of functionality. Hsp 27 can protect cells through molecular interaction with other signaling pathway molecules under stressful conditions. Typically, there are only one HSP 27 gene in prokaryotic cells and a plurality of Hsp 27 protein isoforms with different gene coding in all eukaryotic cells (Lama et al., 2017).

There are 12 members in human Hsp 27 family, of which the most important ones are the Grp78/Bin of inducible, constitutive, and endoplasmic reticulum expressions, as well as the HSPA12B that was recently cloned in human atherosclerotic plaques. All subtypes play an influential role in the regulation of cell homeostasis, but with different effects and distribution. Ischemic pre-conditioning and post-conditioning can induce increased expression of Hsp 27, which can protect the tissue from ischemia reperfusion injury, thus constituted an endogenous protective mechanism. Studies have reported that Hsp 27 can protect cerebral ischemia reperfusion injury (Sadowska-Krępa et al., 2017), increased Hsp 27 could reduce azithromycin-induced cardiac cell death (Kumar et al., 2016), and Hsp 27 can alleviate cerebral ischemia reperfusion injury (Mohammadi-Ostad-Kalayeh et al., 2017). This research found that, compared with the ischemic control group, Hsp 27 and Hsp 27 levels increased significantly after medication, suggesting that the protective effect of Antelope horn on cerebral ischemia reperfusion is correlated with the elevation of Hsp 27 and Hsp 70.

\section{Conclusion}

In conclusion that Antelope horn can reduce focal cerebral ischemia reperfusion injury. The reduction of degeneration and apoptosis suggests the correlation between the therapeutic effect of Antelope horn on ischemia reperfusion injury and its anti-apoptotic protective effect.

\section{References}

Chen, Y. K., Zhang, L., Ni, J. S., Wang, X. Y., Cheng, J., Li, Y. C., Zhen, X., Cao, T., \& Jia, J. (2016). LLDT-8 protects against cerebral ischemia/ reperfusion injury by suppressing post-stroke inflammation. Journal of Pharmacological Sciences, 131(2), 131-137. http://dx.doi. org/10.1016/j.jphs.2016.05.003. PMid:27286958.

Chen, Z., Xu, J. Y., Sun, C. J., Ren, D. X., Zou, H. M., Tian, S. C., \& Li, Y. X. (2017). Study on association of HSP70_hom gene polymorphism with rheumatoid arthritis using capillary electrophoresis-laser induced fluorescence. Microchemical Journal, 2017, 155-161.

Chrzan, R., Gleń, A., \& Urbanik, A. (2017). Hyperdense middle cerebral artery sign as the only radiological manifestation of hyperacute ischemic stroke in computed tomography. Neurologia i Neurochirurgia Polska, 3, 23-29. PMid:28341040.

Fan, J., Yu, S., Cui, Y., Xu, G., Wang, L., Pan, Y., \& He, H. (2017a). $\mathrm{Bcl}-2 / \mathrm{Bax}$ protein and mRNA expression in yak (Bos grunniens) placentomes. Theriogenology, 104, 23-29. PMid:28806624.

Fan, X., Xi, H., Zhang, Z., Liang, Y., Li, Q., \& He, J. (2017b). Germ cell apoptosis and expression of $\mathrm{Bcl}-2$ and $\mathrm{Bax}$ in porcine testis under normal and heat stress conditions. Acta Histochemica, 119(3), 198204. PMid:28279507.

Gumbinger, C., Reuter, B., Stock, C., Sauer, T., Wiethölter, H., Bruder, I., Rode, S., Kern, R., Ringleb, P., Hennerici, M. G., Hacke, W., \& Schlaganfall, A. G. (2014). Time to treatment with recombinant tissue plasminogen activator and outcome of stroke in clinical practice: retrospective analysis of hospital quality assurance data with comparison with results from randomized clinical trials. $B M J$, 348(3), g3429. http://dx.doi.org/10.1136/bmj.g3429. PMid:24879819.

Kumar, S., Stokes, J. 3rd, Singh, U. P., Scissum Gunn, K., Acharya, A., Manne, U., \& Mishra, M. (2016). Targeting hsp70: a possible therapy for cancer. Cancer Letters, 374(1), 156-166. http://dx.doi. org/10.1016/j.canlet.2016.01.056. PMid:26898980.

Lama, R., Gan, C., Idippily, N., Bobba, V., Danielpour, D., Montano, M., \& $\mathrm{Su}, \mathrm{B}$. (2017). HMBA is a putative HSP70 activator stimulating HEXIM1 expression that is down-regulated by estrogen. The Journal of Steroid Biochemistry and Molecular Biology, 168, 91-101. http:// dx.doi.org/10.1016/j.jsbmb.2017.02.008. PMid:28213333. 
Lis, K., Grygorowicz, T., Cudna, A., Szymkowski, D. E., \& BałkowiecIskra, E. (2017). Inhibition of TNF reduces mechanical orofacial hyperalgesia induced by Complete Freund's Adjuvant by a TRPV1dependent mechanism in mice. Pharmacological Reports, 2(6), 149-152. PMid:29132095.

Mohammadi-Ostad-Kalayeh, S., Hrupins, V., Helmsen, S., Ahlbrecht, C., Stahl, F., Scheper, T., Preller, M., Surup, F., Stadler, M., Kirschning, A., \& Zeilinger, C. (2017). Development of a microarray-based assay for efficient testing of new HSP70/DnaK inhibitors. Bioorganic \& Medicinal Chemistry, 25(24), 6345-6352. http://dx.doi.org/10.1016/j. bmc.2017.10.003. PMid:29042222.

Sadowska-Krępa, E., Klapcinska, B., Jagsz, S., Nowara, A., SzoltysekBoldys, I., Chalimoniuk, M., Langfort, J., \& Chrapusta, S. J. (2017). High-dose testosterone enanthate supplementation boosts oxidative stress, but exerts little effect on the antioxidant barrier in sedentary adolescent male rat liver. Pharmacological Reports, 69(4), 673-678. http://dx.doi.org/10.1016/j.pharep.2017.02.023. PMid:28531762.

Sarkar, S., Mukherjee, A., Das, N., \& Swarnakar, S. (2017). Protective roles of nanomelatonin in cerebral ischemia-reperfusion of aged brain: matrixmetalloproteinases as regulators. Experimental Gerontology, 92, 13-22. PMid:28285147.

Shichita, T., Hasegawa, E., Kimura, A., Morita, R., Sakaguchi, R., Takada, I., Sekiya, T., Ooboshi, H., Kitazono, T., Yanagawa, T., Ishii, T., Takahashi, H., Mori, S., Nishibori, M., Kuroda, K., Akira, S., Miyake, K., \& Yoshimura, A. (2012). Peroxiredoxin family proteins are key initiators of post-ischemic inflammation in the brain. Nature Medicine, 18(6), 911-917. http://dx.doi.org/10.1038/ nm.2749. PMid:22610280.

Wang, W. Z., Liu, L. X., Jiang, P., Chen, C., \& Zhang, T. (2016). Levodopa improves learning and memory ability on global cerebral ischemiareperfusion injured rates in the Morris water maze test. Neuroscience Letters, 201, 245-250.

Zhang, X., Xue, X. J., Zhao, J., Qian, C. X., Guo, Z. J., Ito, Y., \& Sun, W. (2016). Diosgenin attenuates the brain injury induced by transient focal cerebral ischemia-reperfusion in rats. Steroids, 113, 103-112. http://dx.doi.org/10.1016/j.steroids.2016.07.006. PMid:27425638. 